\title{
INDICACIONES GEOGRÁFICAS Y DENOMINACIONES DE ORIGEN Propiedad Intelectual en progreso
}

\author{
GEOGRAPHICAL INDICATIONS AND APPELLATIONS OF ORIGIN \\ Intellectual Property in progress
}

\section{CRISTINA ERrÁZURIZ TORTORELLI*}

\begin{abstract}
RESUMEN: El presente trabajo trata el concepto de las indicaciones geográficas y de las denominaciones de origen en cuanto derechos de propiedad intelectual. La autora analiza la evolución de la protección jurídica internacional y chilena de indicaciones geográficas y denominaciones de origen. Al analizar la coyuntura nacional, la autora constata la existencia de un sistema híbrido de protección en el que coexiste protección legal, por tratados internacionales y registral. Finalmente propone que el sistema registral de protección de indicaciones geográficas y denominaciones de origen se extienda para efectos de constituirse en el sistema único de protección.
\end{abstract}

Palabras clave: propiedad intelectual, propiedad industrial, indicaciones geográficas, denominaciones de origen, vino, bebidas espirituosas.

ABSTRACT: This work deals with the concept of geographical indications and appellations of origin as intellectual property rights. The author analyzes the evolution of international and Chilean juridical protection of geographical indications and appellations of origin. When analyzing the national situation, the author considers the existence of a hybrid system of protection in which legal protection coexists with international treaty protection and the Registrar. She proposes that the registration system of geographical indications and appellations of origin be extended so as to constitute a unified system of protection.

Key words: intellectual property, industrial property, geographical indications, appellations of origin, wine, spirits.

\section{INTRODUCCIÓN}

El régimen de protección de las indicaciones geográficas y denominaciones de origen ha experimentado grandes cambios a raíz de la suscripción del Acuerdo de la Organización Mundial del Comercio que incluía la firma del Acuerdo sobre los Aspectos de Propiedad Intelectual relativos al Comercio (ADPIC). Estos cambios también proceden de los tratados de libre comercio suscritos por Chile y de reformas al sistema interno de protección de la propiedad intelectual, realizadas para adecuar la legislación interna a la normativa internacional.

* Licenciada en Derecho, Pontificia Universidad Católica de Chile, Abogada, Magíster en Investigación Jurídica, Universidad de los Andes. 
Como consecuencia, algunas denominaciones de origen chilenas han adquirido protección internacional, mientras que otras han perdido protección en el ámbito interno. En especial, hay que destacar que se ha abierto en la legislación interna un sistema eficaz y flexible de protección, cuyas potencialidades están aún por explorar.

El propósito de este trabajo es examinar este universo de cambios y proponer líneas de desarrollo futuras que podrían mejorar el sistema. Para hacerlo nos proponemos recapitular el desarrollo histórico de estos conceptos en el ámbito de la propiedad intelectual (Parte I). Este recurso histórico pretende explicar ambivalencias y conflictos de intereses en el plano internacional e incluso el estado actual de la legislación chilena. Esto último es examinado en la segunda parte del estudio (Parte II).

En esta última parte, trazaremos el desarrollo de las diversas técnicas de protección actualmente vigentes y propondremos su refundición en un sistema único o, a lo menos, dual de protección. Este sistema aportaría claridad y dotaría a los productores de herramientas jurídicas cuya eficacia se ha demostrado por el sistema de protección de la propiedad intelectual.

\section{PARTE I}

\section{EL DESARROLLO DE LAS INDICACIONES GEOGRÁFICAS Y DENOMINACIONES DE ORIGEN EN EL ÁMBITO DE LA PROPIEDAD INTELECTUAL}

\section{EL VINO FRANCÉS Y EL DESARROLLO DE LAS DENOMINACIONES DE ORIGEN EN EL SECTOR VITIVINÍCOLA}

\section{a) Formación del concepto}

Las indicaciones de procedencia geográfica, entre las que se enmarcan las denominaciones de origen, nacieron con la costumbre de designar a los productos con el nombre del lugar de su producción o fabricación. El asentamiento de personas en zonas específicas, y el aprovisionamiento de materias primas en los lugares de fabricación, condujeron a los productores a componer sus marcas con los nombres geográficos de los lugares, siendo su uso compartido por el conjunto de fabricantes de un producto determinado de la misma ciudad o región. Roquefort es un ejemplo de ello, cuando en el siglo XIV Carlos V concedió a los habitantes de Roquefort el uso exclusivo de este nombre para distinguir queso madurado en las cuevas de la región. En el mismo siglo, Francia estableció normas que prohibían darle al vino de una región otro nombre que aquel donde se había elaborado ${ }^{1}$.

El uso de indicaciones geográficas y denominaciones de origen es la natural consecuencia de productos de calidad que gozan de buena reputación. Desde tiempos inmemoriales ha existido una estrecha relación entre la naturaleza del suelo y la calidad específica de los vinos ahí producidos. Si bien hay noticia del uso de indicaciones

${ }^{1}$ SCHIAVONE (2003) p. 17. 
de procedencia geográfica para designar productos en jeroglíficos egipcios y textos bíblicos, es en épocas modernas cuando las denominaciones de origen fueron implantadas en Francia en el siglo XIX, para pasar luego a países vecinos como España, Italia y Portugal ${ }^{2}$.

El desarrollo normativo se inicia con posterioridad a la destrucción de los viñedos franceses por la plaga de filoxera en 1870 y el desabastecimiento que la siguió: se fabricaban grandes cantidades de vinos con prácticas fraudulentas. Por otra parte, como los viñedos del sur se reconstituyeron más rápido, muchos vinos usurpaban nombres célebres como Burdeos o Borgoña, siendo en realidad procedentes de otras regiones ${ }^{3}$.

Se considera que la denominación de origen más antigua en el mundo se concedió en 1887 al Sindicato de los Grandes Marqueses de Champagne, cuando Francia reconoció la propiedad exclusiva del nombre Champagne para los vinos espumosos de esa región ${ }^{4}$.

La buena reputación de los vinos franceses, y el hecho de que su calidad estaba fuertemente vinculada al origen geográfico de los mismos, favorecieron que fuera esta industria la que mayor impulso dio al desarrollo y protección de las denominaciones de origen. Francia fue el principal interesado en la formación de la Oficina Internacional del Vino (hoy sucedida por la Organización Internacional del Vino - OIV), el 29 de noviembre de 1924, con sede en París. El artículo $1^{\circ}$ del Acuerdo de Creación de una Oficina Internacional del Vino en París señala que esta oficina estará encargada de someter a los gobiernos todas las propuestas susceptibles de asegurar, en el interés del consumidor final como del productor, la protección de las denominaciones de origen de los vinos (artículo 1 letra e).

En la actualidad, el ámbito de aplicación de las denominaciones de origen se ha mantenido estrechamente relacionado a los vinos y las bebidas alcohólicas, si bien hay otros productos que igualmente tienen características fuertemente vinculadas a su origen geográfico, y que por analogía serían susceptibles de este tipo de protección.

\section{b) Indicaciones geográficas y denominaciones de origen: conceptos relacionados}

A título preliminar es necesario distinguir conceptos que se repiten en diferentes textos y regulaciones para designar el objeto de nuestro estudio. Denominación de origen, indicación geográfica e indicación de procedencia son nombres que apuntan a bienes jurídicos semejantes. Para efectos de nuestro estudio usaremos los términos indicaciones geográficas y denominaciones de origen ya que son los empleados por la legislación chilena, sin perjuicio de referirnos a las indicaciones de procedencia cuando así lo hacen los ordenamientos o autores particulares que mencionaremos.

La denominación de origen es una especie de indicación geográfica, tratándose de derechos de propiedad intelectual en sentido amplio, al igual que las marcas y patentes 5 .

\footnotetext{
2 ÁLVAReZ (2001) pp. 93-94.

3 SCHIAVONE (2003) p. 17.

${ }^{4}$ OrozCo (2008) p. 391.

5 En este sentido, Acuerdo sobre los Aspectos de Propiedad Intelectual relativos al Comercio - ADPIC, artículo 1.2 y parte II sección 3 .
} 
La indicación geográfica es una expresión o signo utilizado para indicar procedencia; es decir, que un producto o servicio tiene su origen en un determinado país o grupo de países, región o localidad ${ }^{6}$.

Desde el punto de vista de sus funciones, las indicaciones geográficas se pueden clasificar en indicaciones geográficas simples y calificadas. Las simples se refieren a un lugar reconocido como centro de producción o transformación de productos. Su función es simplemente referencial, sin vincular origen con calidad o características específicas, más allá de las que puedan atribuirse exclusivamente al lugar geográfico. Se trata de indicaciones de procedencia que se limitan a señalar el origen geográfico ${ }^{7}$.

Las indicaciones geográficas calificadas se refieren a los nombres geográficos que designan un producto originario de ese territorio (zona, región, provincia, país), cuya función es informar sobre ciertas cualidades o características, la fama o reputación, imputables fundamentalmente a su origen geográfico, comprendiendo los factores naturales o humanos. Dentro de esta clase, encontramos denominaciones de origen que registran subclases: denominaciones de origen controladas (sujetas a regulación y control de la autoridad), denominaciones de origen registradas (sujetas a registro), denominaciones de origen calificadas y garantizadas (que hacen referencia a una mayor calidad y control del producto $)^{8}$.

Las denominaciones de origen forman una categoría de las indicaciones geográficas, y sirven para designar un producto originario de un país, región o localidad cuando la calidad o las características de ese producto se deben exclusiva o esencialmente al medio geográfico, incluidos los factores naturales y humanos ${ }^{9}$. Las denominaciones de origen consideran más exigencias para ser concedidas y, por tanto, tienden a ofrecer una protección mayor que las indicaciones geográficas en los ordenamientos jurídicos en que ambas son protegidas.

Lo que distingue a las denominaciones de origen son los factores naturales y humanos, que, presentes en ellas, faltan en las indicaciones geográficas simples. En el caso del vino, entre los factores naturales se destacan la naturaleza del suelo, los cepajes utilizados, el clima, los índices de pluviometría, la distribución de lluvias, humedad ambiental, luminosidad, temperatura, altitud, vientos, etc. Por su parte, entre los factores humanos están los trabajos de conservación de suelos, riegos, drenaje, prácticas de cultivo, técnicas de conducción de la vid, vinificación, elaboración, combinación de cepajes y guarda, entre otros ${ }^{10}$.

Cada denominación de origen debe tener un reglamento interno que defina las condiciones de uso de la denominación. Este reglamento constituye un elemento fundamental de la denominación en cuanto determina las características del producto, y la concurrencia de las condiciones necesarias para que pueda utilizar la denominación de origen en particular.

\footnotetext{
${ }^{6}$ LARRAGUibEL (1995) p. 119.

7 SCHIAVONE (2003) p. 19.

${ }^{8}$ SCHIAVONE (2003) p. 19.

${ }^{9}$ LARRAGUibel (1995) p. 119.

10 ÁLVAREZ (1998) p. 780.
} 
Por estas características especiales, la denominación de origen aspira a un reconocimiento mayor que la indicación geográfica, y su uso se ha circunscrito, principalmente, al ámbito del derecho del vino y de las bebidas espirituosas, sirviendo para indicar las características que hacen diferente a un vino en particular respecto de otro, asegurando al consumidor su superioridad, autenticidad respecto de su origen geográfico, cepas utilizadas en su elaboración, normas estrictas de control de calidad y protegiendo al productor que acata reglas de producción y elaboración. Las denominaciones de origen establecidas por ley requieren que el legislador defina las áreas geográficas de producción, cepas utilizadas, características de la producción y que además establezca sanciones por el no cumplimiento de los requisitos establecidos en la ley ${ }^{1}$.

En un mismo lugar geográfico pueden existir vinos con denominación de origen y otros con indicación geográfica. Las indicaciones geográficas solo se referirán al nombre del lugar donde fue producida la uva, donde fue hecha la vinificación, el embotellado o el envejecimiento; en cambio, en las denominaciones de origen todas estas prácticas deberían ser hechas en la misma zona, según lo establezca la ley o el reglamento respectivo ${ }^{12}$.

Las denominaciones de origen tienen un ámbito material de aplicación objetivo: productos vinícolas primero, para luego extenderse hacia otros productos agrícolas y alimentarios. En el caso de productos industriales o artesanales no agrícolas, comúnmente se utilizan las indicaciones geográficas simples, como encajes de Bruselas, aceros de Toledo, porcelanas de Limoges o cristales de Murano ${ }^{13}$.

A diferencia de las indicaciones geográficas simples, las denominaciones de origen no se aplican a cualquier producto agrícola o alimentario, sino únicamente a aquellos que vinculan una cualidad o particularidad al origen geográfico. Los commodities agrícolas, los productos masificados o de similares características sin importar su procedencia, no son susceptibles de esta protección, quedando reservadas las denominaciones de origen para los productos de una labor artesanal. El arroz, la soya y los granos son productos que, manteniendo una calidad homologable sin importar su procedencia, no son susceptibles de protección por denominación de origen. No obstante, esta regla se ve alterada cuando un producto determinado adquiere características especiales posteriores, atribuibles tanto a la intervención del hombre como a razones climáticas y de suelo, como es el caso del arroz Basmati ${ }^{14}$.

Las denominaciones de origen diferencian y dan valor a los productos que distinguen. Sirven a los consumidores en cuanto dan garantías respecto de la calidad de productos determinados, tienen ventajas económicas al promover alianzas y asociaciones de empresas pequeñas y medianas y la exportación de distintas especialidades, generando riqueza al país y a las respectivas economías regionales. Además, tienen claras repercusio-

\footnotetext{
${ }^{11}$ Álvarez (2001) p. 98.

12 Álvarez (2001) p. 98.

${ }^{13}$ SCHiavone (2003) p. 20.

${ }^{14} \mathrm{El}$ arroz Basmati es un arroz producido en el norte de la India, de gran atractivo por su particular aroma perfumado y su grano suave y largo.
} 
nes ambientales, ya que constituyen el nexo entre el producto y la tierra, y por lo mismo, contribuyen a asegurar técnicas de producción sustentables ${ }^{15}$.

Es por esto que las regulaciones sobre indicaciones geográficas y denominaciones de origen se relacionan con una estrategia económica de productores y países, y el desarrollo de mayor competitividad para el sector de las especialidades alimenticias, tanto en el mercado local, regional o mundial. Casos como Café de Colombia ${ }^{16}$ nos pueden servir de ejemplo del desarrollo comercial que se puede obtener a partir de una indicación geográfica.

\section{c) Naturaleza jurídica de la protección}

Definir el tipo de protección al que deben ser acreedoras las indicaciones geográficas y las denominaciones de origen, es asunto de larga data. A principios del siglo XX se buscaba evitar el fraude a los consumidores y proteger a los productores respecto de quienes usaran indicaciones de procedencia falsas. Este objetivo se lograba a través de la protección en contra de la competencia desleal y la protección al consumidor. En la medida que la protección de indicaciones geográficas y denominaciones de origen fue evolucionando, su protección legal hacía que esta se centrara en la aplicación de sanciones administrativas en contra de quienes mal utilizaran denominaciones de origen. Finalmente, su incorporación definitiva como derechos de propiedad intelectual permite accionar los mecanismos legales propios de este tipo de derechos que contienen las legislaciones locales. De esta manera pueden darse casos de querellas criminales, juicios de nulidad o de oposición y acciones de indemnización de perjuicios en casos de infracción.

$\mathrm{Al}$ incluir las indicaciones geográficas entre los derechos de propiedad intelectual se usa este término en sentido amplio, abarcando tanto al derecho de autor como a la propiedad industrial, que a su vez incluye a las indicaciones geográficas y denominaciones de origen.

El sistema jurídico del derecho continental tendió a separar la propiedad industrial de la intelectual, asimilando esta última exclusivamente al ámbito del derecho de autor y derechos conexos. Es así como las normas chilenas sobre los derechos de autor han usado la expresión "propiedad intelectual” en su designación. Es el caso de la "Ley de Propiedad Intelectual” No 17.336, del año 1970, actualmente vigente, si bien ya en 1930 el profesor Luis Claro Solar sostenía que el término era genérico para designar cuatro especies o formas de propiedad: propiedad literaria, propiedad dramática, propiedad artística y propiedad industrial ${ }^{17}$. Autores de más reciente data coinciden en que la propiedad intelectual incluye tanto a los derechos de autor y derechos conexos, como a la propiedad industrial, e incluso a nuevas formas de propiedad o derechos de uso exclusivo como son los nombres de dominio de Internet ${ }^{18}$.

\footnotetext{
15 SChiavone (2003) p. 21.

${ }^{16}$ Café de Colombia es una indicación geográfica protegida por la Unión Europea. Constituye la primera indicación no europea en recibir este reconocimiento.

${ }^{17}$ Claro Solar (1930) p. 571.

18 Ruiz-TAgle Vial (2001) pp. 30-31; SCHMitz (2005) pp. 17-20.
} 
La confusión terminológica se advierte también en España, donde aún se utiliza la expresión propiedad intelectual para referirse a los derechos de autor, sin perjuicio de que es equívoca y contradictoria con los tratados internacionales vigentes ${ }^{19}$. Lo mismo sucede en Chile debido a que los tratados internacionales sobre propiedad intelectual de los que nuestro país es parte, incluyen entre los derechos de propiedad intelectual a marcas comerciales, nombres de dominio, indicaciones geográficas, patentes, diseños, derechos de autor, derechos conexos, e incluso la topografía de semiconductores y las bases de datos ${ }^{20}$.

Aclarada esta distinción terminológica comprobamos que en el derecho comparado se han articulado distintas formas de abordar la protección de las indicaciones geográficas y denominaciones de origen. Hay autores que consideran que la diferencia entre las indicaciones geográficas simples y las calificadas, entre las que se encuentran las denominaciones de origen, tiene consecuencias en el grado de correlación entre las características del producto con su lugar de producción, lo que a su vez incide sobre la naturaleza de la protección. Mientras que las indicaciones geográficas simples se basan en la disciplina de la competencia desleal y de la protección al consumidor, relacionándose con la correcta identificación de las mercaderías, en el caso de las calificadas, se constituye un título que permite excluir su uso a terceros, en el campo de la propiedad intelectual. Esta mayor protección solo se justifica porque el producto designado posee características atribuibles al origen geográfico, y una calidad bajo control y supervi$\operatorname{sió}^{21}$. Tal es el caso de Francia, donde se estableció un sistema de protección legal caracterizado por la división en dos categorías de indicaciones geográficas: indicaciones de procedencia que se protegen por vía de la competencia desleal y legislación especial (Ley de usurpación de denominación de 1905), y las denominaciones de origen, que reciben una protección legal específica (Ley del 6 de mayo, 1919) 22 .

Situación similar se vive en España, donde con el transcurso de los siglos aparecieron normas locales referidas a vinos y aceites de oliva: Sherry, Rioja, Málaga, Ribeiro, Priorato y otras regiones planteaban restricciones a la producción y al comercio. La primera reglamentación en el ámbito nacional es el Estatuto del Vino, de 1932, normativa que presenta la primera definición española de denominación de origen, señalando que el nombre debía ser conocido en el mercado nacional o extranjero, y utilizado para la designación del vino. El Estatuto del Vino también exigía un vínculo entre las características del producto y los factores naturales de la zona geográfica; y se refería a los factores humanos, al decir que los vinos típicos debían responder a las características especiales de producción y a los procedimientos de elaboración y crianza ${ }^{23}$.

\footnotetext{
19 GÓMEZ SEGADE (2001) p. 84.

20 Acuerdo sobre los Aspectos de los Derechos de Propiedad Intelectual relacionados con el Comercio, ADPIC, artículo 1.2 y sección 3; Tratado de Libre Comercio entre Chile y EE.UU., capítulo 17; Acuerdo de Asociación con la Unión Europea, artículo 169.

21 SCHIAVONE (2003) p. 19.

22 Conrad (1996) pp.17-18.

23 SCHIAVONE (2003) p. 18.
} 
En casi todos los Estados que protegen las indicaciones geográficas es posible distinguir el afán de protección de los consumidores de información engañosa, y/o protección en contra de la competencia desleal. De hecho existe un debate entre los miembros de la OMC respecto de si es necesaria una legislación específica para proteger las indicaciones geográficas, o bien si las leyes de protección al consumidor y de competencia desleal son suficientes. Otros miembros de la OMC consideran que la ley de marcas es un medio adecuado para proteger las indicaciones geográficas ${ }^{24}$.

En Alemania se tendió a favorecer una normativa basada en el principio de protección de los consumidores, evaluando la percepción del público donde la competencia se desarrolla para determinar el grado de engaño ${ }^{25}$. Los productos y regiones extranjeras son menos conocidos que los locales, por lo que respecto de aquellas hay una menor probabilidad de que el consumidor sea engañado, ya que no conoce la región en cuestión. Otro problema surge porque los tribunales deben decidir qué es geográficamente descriptivo o susceptible de provocar engaño. En algunos Estados, los jueces se remiten a su propia experiencia como consumidores para decidir; en otros se solicitan encuestas para obtener un parámetro más objetivo. No obstante, al analizar este sistema pareciera que tiene una alta cuota de arbitrariedad considerando los preconceptos discriminatorios de jueces individuales ${ }^{26}$.

En el derecho comparado, es común que indicaciones geográficas y denominaciones de origen sean protegidas a través de la legislación sobre competencia desleal. Se aplica esta legislación al tratar conductas constitutivas de actos que implican la utilización de una indicación geográfica para productos que no son originarios de la zona indicada, constituye un acto de competencia desleal para los productores originarios y puede inducir a error y a confusión a los consumidores en cuanto al verdadero lugar de origen de los bienes ${ }^{27}$.

La Australian Trade Practices Act de 1974 provee de un número de prohibiciones sobre competencia desleal en el comercio que puede ser usada para proteger todo tipo de indicaciones geográficas. Estas provisiones previenen el engaño o posible daño e implícitamente protegen a las indicaciones geográficas ${ }^{28}$.

Por su parte Estados Unidos protege las indicaciones geográficas por medio del sistema marcario, en particular como marcas colectivas o de certificación ${ }^{29}$. A modo de ejemplo, el registro US $\mathrm{N}^{\circ} 571,798$ protege la marca de certificación Roquefort, para

\footnotetext{
24 O'CONNOR (2004) p. 360.

25 CONRAD (1996) p. 17.

26 CONRAD (1996) p. 17.

27 LORENZINI (2000) p. 108.

28 RISANG AYU (2006) p. 9.

29 La United States PATENT AND TRAdemark Office señala que la marca colectiva es la marca comercial de los miembros de una cooperativa, asociación u otro grupo colectivo u organización, incluyendo la marca que indica membresía en la unión, asociación u otra organización. La marca de certificación es aquella que se utiliza para certificar el origen regional o geográfico, el material, modo de manufactura, calidad, precisión u otras características de los bienes o servicios de otros, o que el trabajo sobre los bienes o servicios se realizó por miembros de una unión u otra organización. Ver http://www.uspto.gov/main/faq/ index.html
} 
distinguir queso fabricado con leche de cabra y madurado en las cuevas de la comunidad de Roquefort, Francia, de acuerdo a sus métodos y procesos ${ }^{30}$.

En Chile, por modificación de la Ley de propiedad industrial en el año $2005^{31}$, tanto indicaciones geográficas como denominaciones de origen son derechos de propiedad industrial, otorgando un título que permite excluir su uso a terceros, ejerciendo las acciones legales establecidas por dicha ley. Además, una conducta puede ser calificada como un acto de competencia desleal conforme a las disposiciones de la Ley 20.169 aunque resulten procedentes respecto de esa misma conducta, y ante los tribunales competentes, una o más de las acciones regladas en la Ley de propiedad industrial (Ley 19.039).

\section{d) Distinción entre indicaciones geográficas y marcas comerciales. El caso}

\section{Parma}

Los productos que compiten en el mercado necesitan diferenciarse, lo que se ha logrado tradicionalmente a través de las marcas comerciales. Al igual que estas, las indicaciones geográficas son signos que permiten distinguir productos idénticos o similares de productores diferentes. Tanto la marca comercial como la indicación geográfica o denominación de origen proporcionan al consumidor elementos de información sobre los diversos productos, para ayudarlo a elegir. Esto se logra gracias al goodwill asociado a la marca. Se trata de una función indicadora de calidad según la cual la marca sintetiza la buena fama o reputación de que gozan entre los consumidores, los productos o servicios distinguidos por la marca ${ }^{32}$.

Esta función es también propia de las indicaciones geográficas y denominaciones de origen. Es precisamente esta función la que justifica la inclusión de las mismas dentro de los derechos de propiedad industrial. Si bien su normativa ha discurrido como categoría independiente, podemos afirmar que guardan una estrecha relación con las marcas comerciales, y en particular con las marcas colectivas o de garantía, pudiendo incluso considerarse como una especie dentro de ese género común ${ }^{33}$. No obstante, hay suficientes diferencias entre las indicaciones geográficas y las marcas colectivas como para justificar su independencia.

Las indicaciones geográficas y denominaciones de origen se diferencian de las marcas comerciales en cuanto las primeras son términos que corresponden al lugar de origen de los productos, mientras que las segundas son signos originales que sirven para distinguir un producto determinado de aquellos con los que compite en el mercado. Las indicaciones geográficas servirán para distinguir los productos de muchos fabricantes distintos, asentados en la misma zona, que luego podrán usar diferentes marcas al momento de comercializar sus productos. El origen geográfico juega un rol fundamental en

30 United States Patent and Trademark Office (en http://www.uspto.gov/web/offices/dcom/olia/ globalip/pdf/gi_system.pdf).

${ }^{31}$ Ley 19.996, de 2005, que modificó la Ley 19.039.

${ }^{32}$ FERNÁNDEZ (2005) p. 76.

${ }^{33}$ LÓPEZ (1996), p. 25. 
el caso de las denominaciones de origen, que sirven como signos de tradiciones de larga data en los procesos y la calidad esperada respecto de determinados productos ${ }^{34}$.

Las marcas tienden a tener un titular único. Por su misma naturaleza, las indicaciones geográficas tienen un titular colectivo e indeterminado, ya que bastaría con asentarse en la zona y producir los bienes específicos para poder utilizar el nombre. A simple vista, podría parecer que las marcas colectivas escapan de esta regla general de titularidad única, pero no es así porque estas tienen por titular a una entidad colectiva que actúa como único dueño, la que es regida por un reglamento interno que controla las relaciones entre los miembros de la colectividad.

En Estados Unidos se privilegia el sistema marcario, por el cual una indicación geográfica puede registrarse al igual que las marcas colectivas o de certificación, sin perjuicio que se establezcan derechos sobre la denominación por el common law. A diferencia de las marcas que se registran sobre la base del primero en solicitarla, la "first to file rule", las indicaciones geográficas se registran sobre la base de quien detenta un mejor derecho para su registro, la "better right rule" 35 . En caso de un conflicto entre una marca previa y una indicación geográfica posterior, tiene prioridad la marca ${ }^{36}$.

Por el contrario, en Europa el sistema privilegia a las indicaciones geográficas por sobre las marcas comerciales, considerando que las primeras tienen mejor derecho que las segundas.

Frente a dos sistemas que parecen antagónicos, cabe preguntarse si no debiera prevalecer una solución que busque la equidad, donde marcas e indicaciones geográficas o denominaciones de origen puedan coexistir con los resguardos respectivos.

Los casos Embutidos Parma ${ }^{37}$ y Jamón Parma ${ }^{38}$, sucedidos en Estados Unidos y Canadá, respectivamente, son un claro ejemplo del conflicto que puede producirse entre una marca y una indicación geográfica.

Ambos casos son similares, ya que se trataba de productores locales que habían registrado y usado la marca PARMA antes de que el Consorzio del Prosciutto di Parma buscara el registro como indicación geográfica en cada país. Ambas posturas parecían legítimas, en cuanto se trataba de registros marcarios concedidos décadas antes (1969 y 1971, respectivamente) para distinguir productos derivados de la carne, entre ellos jamón.

El Tribunal de Apelación de Marcas resolvió el primer caso en favor del titular de la marca previa, Parma Sausage Products Inc., considerando que al momento de su registro el signo PARMA no era descriptivo de una región geográfica ya que el público norteamericano no la asociaba a los prosciuttos producidos en Italia. Si bien esta situación habría cambiado en la actualidad, se debía considerar la situación del momento del registro y no la situación actual.

\footnotetext{
${ }^{34}$ GANGJEE (2007) p. 1267.

35 TORSEN (2005) p.1417.

36 GANGJEE (2007) p. 1264.

37 Consorzio del Prosciutto di Parma v. Parma Sausage Products Inc., 23 U.S.P.Q.2d (BNA) 1894, 1992 WI. 2333379 (T.T.A.B. 1992).

38 Consorzio del Prosciutto di Parma v. Maple Leaf Meats Inc. [2001] F.C. 536 (Fed. Ct.) y [2002] Federal Court of Appeals 169.
} 
El segundo caso resuelto en Canadá, fue muy similar y también terminó con una decisión en favor del titular de marca, Maple Leaf Meats Inc., quien había registrado y usado su marca durante años. La corte determinó que a la fecha de su registro, la marca no era deceptively misdescriptive o no distintiva, ya que a esa fecha, PARMA no tenía suficientes connotaciones italianas, a pesar de que en el etiquetado se utilizaran colores de la bandera italiana y palabras en idioma italiano.

Frente a estos casos cabe la pregunta de cómo lograr una solución equitativa. Los derechos de los titulares de marcas deben ser respetados, en cuanto se trata de registros obtenidos en forma previa a que se estableciera protección para la indicación geográfica. Al mismo tiempo no parecería adecuado que el Prosciutto di Parma tuviera que usar otro nombre para ingresar a los mercados de Estados Unidos y Canadá. Afortunadamente en ambos países, con posterioridad a los fallos antes señalados, se llegó a acuerdos que permitieron al Consorzio registrar algunas variantes de sus marcas, con lo que se logró la coexistencia de las marcas con la indicación geográfica. Este resultado parece equitativo, ya que en la práctica vemos que hay casos en los que se justifica la coexistencia, sin producir error en el público. Cabe considerar que el público consumidor de productos alimentarios de renombre tiende a ser más instruido en estos aspectos que el común. Por esta razón la confusión del público, como corolario axiomático de coexistencia, no debe ser presumida con liviandad ${ }^{39}$.

\section{RÁPIDA INTERNACIONALIZACIÓN DE LA PROTECCIÓN}

La necesidad de contar con instrumentos internacionales que protegieran eficazmente indicaciones geográficas y denominaciones de origen, quedó rápidamente en evidencia. Por tratarse de productos de buena reputación, había quienes buscaban aprovechar la fama ajena indebidamente. Sin una adecuada protección internacional no había protección eficaz, ya que los productos falsos afectarían la reputación de los originales en forma irremediable.

El derecho internacional ha contemplado la protección de las indicaciones geográficas y denominaciones de origen dentro del marco de protección de la propiedad intelectual, como una manera de reconocer que se trata de bienes intangibles susceptibles de apropiación, que tienen legítimo titular y son activos de valor en el comercio internacional. A lo anterior se agrega la necesidad de proteger a los consumidores globalizados frente a la confusión o engaño al que pueden verse expuestos a falta de una correcta protección y resguardo de las indicaciones geográficas y denominaciones de origen.

La internacionalización de indicaciones geográficas y denominaciones de origen se produjo a través de los siguientes acuerdos: Convenio de la Unión de París de 1883, Arreglo de Madrid de 1891, Arreglo constitutivo de la Oficina Internacional del Vino de 1924, Arreglo de Lisboa de 1958 y el Acuerdo sobre los Aspectos de Propiedad Intelectual relativos al Comercio de 1995.

39 En este sentido GANGJEE (2007) p. 1290. 


\section{a) Convenio de París de 1883 y evolución}

La Exposición Internacional de París de 1878 marcó el inicio de la conciencia internacional sobre la importancia de proteger la propiedad industrial. La Unión General para la Protección de la Propiedad Industrial se funda con el objetivo de buscar soluciones a los cada vez más complicados problemas que suscita el comercio internacional. En la reunión anual de 1883 se adopta el Convenio de la Unión de París sobre la Propiedad Industrial donde aparecen las primeras normas internacionales sobre represión de las indicaciones de procedencia falsas o engañosas ${ }^{40}$.

El Convenio no define, pero sí incluye, a las indicaciones de procedencia y denominaciones de origen entre los objetos de protección enunciados en el artículo primero. El compromiso que adoptan los países miembros de este convenio es el de embargar, al momento de su importación, todas las mercaderías que utilicen, en forma directa o indirecta, una indicación falsa de procedencia (artículo 10.1).

Se crea la Unión para la Protección de la Propiedad Industrial cuya finalidad es proteger las marcas de fabricación, los nombres comerciales, las indicaciones de procedencia y denominaciones de origen. El convenio busca asegurar que se sancione el uso de indicaciones falsas de procedencia, otorgando la calidad de "parte interesada" para reclamar tal sanción, a toda "persona física o moral, todo productor fabricante o comerciante dedicado a la producción, la fabricación o el comercio de ese producto y establecido en la localidad falsamente indicada como lugar de procedencia, o en la región donde esta localidad esté situada, o en el país falsamente indicado, o en el país donde se emplea la indicación falsa de procedencia” (artículo 10.2).

Las críticas del Convenio se centran en que sus normas son excesivamente generales y vienen referidas a toda indicación falsa, término más amplio que el de las indicaciones geográficas o denominaciones de origen. Se trata de disposiciones tendientes a reprimir fraudes comerciales en general, cuya sanción se logra por medio de los mecanismos de represión de la competencia desleal ${ }^{41}$.

\section{b) El Arreglo de Madrid para la represión de indicaciones falsas o engañosas} sobre el origen de los productos de 1891

Menos de una década después, los países suscriptores del Convenio de París, especialmente interesados en la protección de las indicaciones de procedencia, suscribieron el Arreglo de Madrid relativo a la represión de las indicaciones de procedencia falsas o engañosas en los productos, de 14 de abril de 1891. Este tratado se refiere exclusivamente a la protección de las indicaciones de procedencia de productos en el comercio internacional, y no internamente en cada país miembro de la Unión, previendo la represión de las indicaciones de procedencia engañosas, incluso si no son falsas.

\footnotetext{
40 El Convenio de París ha sido revisado y modificado en varias ocasiones: 1900, 1911, 1925, 1934, 1958, 1967 y 1979. Chile adhirió al Convenio mediante Decreto $\mathrm{N}^{\circ} 425$ que promulga el Convenio de París para la Protección de la Propiedad Industrial, publicado en el Diario Oficial de 30 de septiembre, 1991. El Convenio se encuentra vigente.

41 López (1996) p. 40.
} 
Este tratado introduce la noción de represión de las indicaciones de procedencia falsas, proveyendo una protección mucho más fuerte para las indicaciones de procedencia y denominaciones de origen que el Convenio de París. El Arreglo previene la dilución de indicaciones geográficas a términos genéricos ya que prohíbe el uso de indicaciones capaces de engañar al público, e impide la importación de bienes que utilizan indicaciones falsas o engañosas ${ }^{42}$.

Debido a lo exigente de sus provisiones, el Arreglo de Madrid no ha tenido una aceptación lo suficientemente amplia como para tener una influencia gravitante. Ha sido firmado por 35 Estados, entre los que no se cuentan la mayoría de los estados de mayor fuerza económica y política, de manera que tiene una influencia internacional muy limitada ${ }^{43}$. Chile no es miembro de este tratado.

c) La Oficina Internacional del Vino de 1924, hoy Organización de la Viña y el Vino, París, 2001

El Acuerdo que crea la Organización de la Viña y el Vino fue adoptado en París el 3 de abril de 2001, y ha sido ratificado por Chile, tras su aprobación unánime en el Senado. Esta organización sustituye a la Oficina Internacional del Vino, creada por el Convenio del 29 de noviembre de 1924. Su finalidad fue adaptar dicha entidad al nuevo contexto del sector vitivinícola mundial, de sus medios humanos, materiales y presupuestarios, así como de sus procedimientos y reglas de funcionamiento, a fin de responder a los nuevos desafíos y asegurar el futuro vitivinícola mundial ${ }^{44}$.

El Subdepartamento de Viñas y Vinos del SAG es la entidad chilena encargada de mantener la representatividad y presencia del Servicio ante la Organización Internacional de la Viña y el Vino (O.I.V.), y otros organismos técnicos.

En la práctica se ha tratado de una organización de carácter técnico que no ha significado cambios legislativos internos en nuestro país en lo que respecta a la regulación jurídica de las denominaciones de origen. Dada esta naturaleza técnica y su función limitada exclusivamente al vino, ha sido necesario un acuerdo internacional más general que otorgue una protección adecuada a las denominaciones de origen.

\section{d) Arreglo de Lisboa, 1958. Buscando un registro para el Pisco de Perú}

i. Sistema de Lisboa

El Arreglo de Madrid siguió pareciendo insuficiente para los Estados interesados en una fuerte protección a las denominaciones de origen. Por esta razón surge el Arreglo de Lisboa, relativo a la Protección de las Denominaciones de Origen y su Registro Internacional, que trató de satisfacer la necesidad de gozar a nivel internacional de un sistema que facilitara el reconocimiento y la protección de las denominaciones de origen ${ }^{45}$.

42 Calaguas (2006) p. 262.

${ }^{43}$ En este sentido Calaguas (2006) p. 262.

${ }^{44}$ Organización de la ViÑa Y EL Vino.

45 SCHIAVONE (2003) p. 18. 
El Arreglo de Lisboa fue suscrito el 31 de octubre de 1958, y crea un sistema internacional de protección a las denominaciones de origen. Este acuerdo establece que la denominación de origen es "la denominación geográfica de un país, de una región o de una localidad, que sirva para designar un producto originario del mismo y cuya calidad o características se deben exclusiva o esencialmente al medio geográfico, comprendidos los factores naturales y los factores humanos" 46 .

Esta definición incluye los principales rasgos actualmente presentes en las definiciones doctrinales y legales vigentes.

El Sistema de Lisboa se estableció con el propósito de facilitar la protección internacional de las denominaciones de origen. Está administrado por la Oficina Internacional de la Organización Mundial de la Propiedad Intelectual (en adelante OMPI) y lo utilizan 26 partes contratantes del Arreglo de Lisboa. La versión modificada de su Reglamento entró en vigor el 1 de abril de 2002.

El sistema ofrece la posibilidad de obtener la protección de una denominación de origen de uno de los Estados contratantes en la totalidad de los países miembros del Arreglo de Lisboa mediante un trámite único de registro.

Una vez registrada, la denominación de origen goza de protección en todos los Estados miembros, quienes deben adoptar leyes locales para prohibir no solo imitaciones, sino también productos que indicando su verdadero lugar de procedencia, incluyan los términos "como", "tipo", o "estilo". Además, el sistema de Lisboa señala que cuando la denominación es protegida en el país de origen, no podrá ser considerada genérica en ningún otro Estado miembro (artículo 6).

El alto grado de exigencia de este acuerdo, atentó contra su buena acogida, por lo que hoy es un tratado que tiene un ámbito de acción muy limitado. No obstante, este es un caso interesante de analizar ya que constituye un serio intento por lograr un registro internacional de denominaciones de origen, tema muy debatido en la actualidad en la Organización Mundial del Comercio.

\section{ii. Registro del Pisco Perú}

Chile no es miembro del Arreglo de Lisboa, del que sí es parte Perú, donde ha abogado en favor del reconocimiento del término Pisco como denominación de origen de uso exclusivo del Perú. Este país considera que la denominación Pisco aplicada a las bebidas espirituosas tiene una relación estrecha con el lugar geográfico donde se produce en ese país, en la localidad de Pisqú, de manera que Perú debiera tener la exclusividad en su uso. Por su parte Chile estima que el término es igualmente aplicable a la bebida destilada producida en Chile a partir de uvas, donde también hay un pueblo llamado Pisco, por lo que la denominación podría ser usada por los dos países.

Más allá del lugar donde el producto haya podido fabricarse primero, la denominación ha sido utilizada para designar el aguardiente de uva producido en ambos países.

46 Arreglo de Lisboa relativo a la Protección de las Denominaciones de Origen y su Registro Internacional de 1958 , artículo 2 . 
En Chile, las regiones de Atacama y Coquimbo han sido delimitadas legalmente para usar el término Pisco ${ }^{47}$.

En julio de 2005, Perú presentó una solicitud de registro internacional de esta denominación de origen ante la Organización Mundial de la Propiedad Intelectual (OMPI), de acuerdo al sistema de Lisboa, que agrupa a 26 países $^{48}$.

En agosto de 2006 se conoció el resultado de la solicitud. Siete Estados europeos, entre los que se contaban Francia, Italia y Portugal, rechazaron la solicitud de registro exclusivo de la denominación de origen Pisco presentada por Perú, únicamente porque obstaculizaría su utilización para productos originarios de Chile, reconocido en virtud del Acuerdo de Asociación Económica entre Chile y la Unión Europea ${ }^{49}$. México también la rechazó "únicamente si constituye un obstáculo para la utilización de productos provenientes de Chile con la denominación Pisco" protegidos por el tratado de libre comercio celebrado entre Chile y México ${ }^{50}$.

Se comprueba cómo la suscripción de tratados comerciales bilaterales ha resultado especialmente provechoso para nuestro país para proteger la denominación de origen Pisco para distinguir el aguardiente producida en nuestro país. En esta misma línea, Estados Unidos de América ${ }^{51}$, Canadá ${ }^{52}$ y Japón ${ }^{53}$ reconocen al Pisco Chileno como producto distintivo de Chile.

Otro antecedente fundamental es que en el Tratado de Libre Comercio suscrito entre Perú y Estados Unidos el 1 de febrero de 2009, el país limítrofe realizó un reconocimiento respecto de que el concepto que les pertenece es "Pisco Perú" y no "Pisco". Esto sienta un importante precedente para que Perú deba incluir esta autolimitación en todos los tratados de libre comercio que tramite a futuro, además de determinar el potencial éxito o fracaso de cualquier pretensión de llevar el tema a la Organización Mundial de Comercio (OMC).

\footnotetext{
${ }^{47}$ JAQUIER y AREYUNA (2004) pp. 113 ss.

48 Argelia, Bulgaria, Burkina Faso, Congo, Costa Rica, Cuba, Francia, Gabón, Georgia, Haití, Hungría, Irán, Israel, Italia, México, Nicaragua, Perú, Portugal, Moldavia, Corea del Norte, República Checa, Serbia y Montenegro, Eslovaquia, Togo y Túnez.

49 Acuerdo por el que se establece una asociación entre la Comunidad Europea y sus Estados miembros, por una parte, y la República de Chile, en vigor desde el 3 de febrero del año 2003, mediante el Decreto $\mathrm{N}^{\circ} 28$.

${ }^{50}$ Argelia, Burkina Faso, Congo, Cuba, Georgia, Haití, Israel, Irán, Nicaragua, Corea del Norte, República de Moldavia, Serbia, Togo y Túnez no se pronunciaron, por lo que de acuerdo a lo establecido en el Tratado de Lisboa, reconocen en forma exclusiva al Perú la denominación "Pisco".

51 Tratado de Libre Comercio entre Estados Unidos de América y Chile, entró en vigor desde el 31 de diciembre del año 2003, mediante el Decreto $\mathrm{N}^{\circ} 312$.

52 Tratado de Libre Comercio entre Canadá y Chile, en vigor desde el 5 de julio de 1997, mediante el Decreto $\mathrm{N}^{\circ} 1.020$.

${ }^{53}$ Acuerdo entre la República de Chile y Japón para una Asociación Económica Estratégica, en vigor desde septiembre de 2007.
} 
e) Acuerdo sobre los Aspectos de Propiedad Intelectual relativos al Comercio (ADPIC), de 1995.

ADPIC entró en vigor el 1 de enero de 1995 y constituye el acuerdo multilateral más completo que existe sobre propiedad intelectual ${ }^{54}$. La convención trata cada una de las principales categorías de derechos de propiedad intelectual, establece normas de protección y reglas para su observancia, y prevé la aplicación del mecanismo de solución de diferencias de la OMC para resolver los litigios entre los Estados Miembros. ADPIC abarca los principales sectores de la propiedad intelectual: derecho de autor y derechos conexos; las marcas comerciales, incluidas las de servicios; indicaciones geográficas; los dibujos y modelos industriales; las patentes de invención, incluida la protección de las obtenciones vegetales; los esquemas de trazado (topografías) de los circuitos integrados; y la información no divulgada, incluyendo los secretos comerciales.

A consecuencia de ADPIC la protección de la propiedad intelectual ha pasado a ser parte integrante del sistema de comercio multilateral de la OMC. Este acuerdo constituye uno de los pilares de la OMC. La idea base que dio origen a la negociación de ADPIC fue que unas normas inadecuadas de protección y una observancia ineficaz de los derechos de propiedad intelectual privaban de manera injusta a los titulares de los derechos de los beneficios resultantes de su creatividad y capacidad inventiva y, en consecuencia, perjudicaban los legítimos intereses comerciales de sus países.

Hasta la fecha, la implementación de ADPIC por la OMC constituye el esfuerzo más importante y logrado en la protección internacional de los derechos de propiedad intelectual, comprendiendo a la gran mayoría de los países del mundo, lo que da a sus disposiciones un alcance universal. El gran impulso para el reconocimiento internacional de las indicaciones geográficas se consagra con su formal inclusión en ADPIC.

La eficacia de ADPIC radica en que se encuentra en el marco de la OMC, donde se requiere aceptar todos los principales acuerdos de la OMC para ser miembro, y donde el incumplimiento por un país de las obligaciones que le impone el Acuerdo sobre los ADPIC puede poner en peligro sus derechos de acceso a los mercados y los beneficios que obtiene de la OMC.

ADPIC trata las indicaciones geográficas en la Parte II, sección 3, artículos 22, 23 y 24 del acuerdo. Define las indicaciones geográficas señalando que identifican un producto como originario del territorio de un Miembro o de una región o localidad de ese territorio, cuando determinada calidad, reputación, u otra característica del producto sea imputable fundamentalmente a su origen geográfico (artículo 22 sección 1$)$.

\footnotetext{
54 El Acuerdo sobre los Aspectos de Propiedad Intelectual relacionados con el Comercio constituye el anexo 1C del Acuerdo de Marrakesh por el que se establece la Organización Mundial del Comercio, el que fue promulgado en Chile por Decreto Supremo $N^{\circ} 16$ del Ministerio de Relaciones Exteriores, el 5 de enero, 1995, publicado en el Diario Oficial el 17 de mayo, 1995.
} 
No hay definición de las denominaciones de origen, ni se nombra el concepto en particular, sino que se ofrece una protección especial para las indicaciones geográficas de vinos y bebidas espirituosas (artículo 23), ya que no hubo el consenso necesario para tratar el tema ${ }^{55}$.

Con el propósito de proteger las indicaciones geográficas extranjeras, ADPIC impone la exigencia de denegar o invalidar el registro de una marca comercial que contenga o consista en una indicación geográfica respecto de productos no originarios del territorio indicado, si el uso de tal indicación en la marca -respecto de esos productos en ese Miembro- es de naturaleza tal que induzca al público a error en cuanto al verdadero lugar de origen.

La protección del consumidor queda establecida con la ampliación del ámbito de protección de las indicaciones geográficas, de manera que se puede evitar su uso aun cuando sea literalmente verdadera en cuanto al territorio, región o localidad de origen de los productos, pero dé al público una idea falsa de que estos se originan en otro territorio.

Al igual que convenios internacionales anteriores sobre propiedad intelectual, ADPIC es un acuerdo de normas mínimas. No obstante su nivel de exigencia supera en tal grado el estándar promedio de protección de la propiedad intelectual de los Estados miembros, que se ha convertido en una norma de armonización entre las legislaciones de los distintos estados ${ }^{56}$.

\section{PARTE II}

\section{LAS DENOMINACIONES DE ORIGEN EN CHILE. DESARROLLO NORMATIVO AMBIVALENTE}

En el ámbito interno podemos observar tendencias muy similares a las que hemos analizado en el ámbito internacional. Comprobamos que la tradición vitivinícola chilena ha favorecido el desarrollo normativo de las denominaciones de origen, circunscritas al vino y a las bebidas espirituosas, en particular al Pisco. No obstante, se vislumbra la confusión entre el concepto de indicación geográfica y denominación de origen. Las indicaciones geográficas propiamente tales, no han sido objeto de regulación jurídica en Chile hasta la modificación de la Ley 19.039 del año 2005 que permitió la adecuación de la legislación chilena a los compromisos adoptados como miembros de la OMC, según las normas de ADPIC.

\footnotetext{
55 ADPIC establece una protección adicional de las indicaciones geográficas de los vinos y bebidas espirituosas que consiste en que se pueda impedir la utilización de una indicación geográfica que identifique vinos o bebidas espirituosas para productos de ese género que no sean originarios del lugar designado por la indicación geográfica de que se trate, incluso cuando se indique el verdadero origen del producto o se utilice la indicación geográfica traducida o acompañada de expresiones tales como "clase", "tipo", "estilo", “imitación” y otras análogas.
} 


\section{BREVE Historia DEL CONCEPTO EN LA LEGISLACIÓN CHILENA. SieMPRE VINCULADO AL VINO}

La Ley de Alcoholes y Bebidas Alcohólicas $N^{\circ} 11.256$ del 16 de julio de 1954, introduce el concepto de denominación de origen en la legislación chilena. Sin embargo, el legislador confunde el término denominación de origen con el de indicación de procedencia o indicación geográfica simple. En el caso del Pisco se limita a exigir que se establezca el origen geográfico de las uvas de las cuales se producía, faltando los elementos naturales o humanos necesarios para que se trate de una denominación de origen. Respecto del Pajarete, el vino generoso de Elqui y de Cauquenes exige que se produzcan en determinadas zonas geográficas por Estaciones Experimentales y Escuelas Agrícolas del Estado, y por asociaciones de productores y viticultores fiscalizados por el Ministerio de Agricultura.

El Decreto con Fuerza de Ley $N^{\circ} 1$ de 1967 establece normas sobre plantaciones, replantes y trasplantes de viñas viníferas y de uvas de mesa, pero incurre en el mismo error antes señalado al definir denominación de origen. Esta norma introduce la prohibición de que la denominación de origen se inscriba como marca comercial (artículo $1^{\circ}$, letra i).

La Ley 17.105 de 1969 sobre alcoholes, bebidas alcohólicas y vinagres, define las denominaciones de origen, indicando que son aquellas que identifican un producto vitivinícola por sus características específicas y por las regiones de que procede, las cuales se señalarán para cada caso (artículo 12, letra i). El Servicio Agrícola y Ganadero (SAG) es el que autoriza el uso de las denominaciones de origen (artículo 13).

En 1979 el Decreto Ley N².753 de Agricultura modifica la Ley 17,105 estableciendo las denominaciones de origen Pisco, Pajarete del Huasco y de Elqui y Vino Asoleado (artículo 15). Se exige que, además de la procedencia geográfica de las vides, los productos resultantes sean producidos y embotellados en las zonas respectivas, sin establecer ningún requisito adicional que haya de cumplir con el fin de obtener un producto de calidad, por lo que también estamos ante un caso de confusión entre denominación de origen e indicación geográfica. El Presidente de la República queda facultado para establecer otras denominaciones de origen en cualesquiera regiones del país, con la única salvedad que no puede alterar o modificar las que quedan establecidas por esta ley (artículo 15 inciso final) ${ }^{57}$.

Los Decretos No 257 de 1979 y Nº 82 de 1980, del Ministerio de Agricultura, establecen denominaciones de origen de acuerdo a la zonificación vitícola establecida por regiones y subregiones territoriales, las que al igual que en los casos anteriores, demuestran que el legislador seguía confundiendo el término denominación de origen

\footnotetext{
56 ADPIC fue ratificado por Chile como parte del paquete de entrada a la OMC. Chile, en su calidad de país en vías de desarrollo, debía contar con la normativa interna adecuada para la completa implementación de las normas contenidas en ADPIC para el año 2000. Esta obligación recién se cumplió en diciembre de 2005, año en el cual se aprueba la Ley 19.996, que modifica al Ley de Propiedad Industrial, logrando la requerida adecuación.

57 Para mayor detalle sobre la historia del concepto de denominación de origen en la legislación chilena, ver ÁLVAREZ (1998) pp. 782 ss.
} 
con el de indicación geográfica, al no exigir ningún requisito adicional de tipo natural o humano que incidiera en la calidad del producto final.

Previo al 11 de marzo de 2005, fecha en que entró en vigencia la reforma de la Ley de Propiedad Industrial, la impresión que existía respecto de la regulación de las indicaciones geográficas y las denominaciones de origen era confusa. Se criticaba la falta de definiciones conceptuales concretas y el uso recurrente de términos vagos e imprecisos. Igualmente era palpable que el legislador había tratado el tema con una falta de sentido de unidad entre las diversas normas dictadas sobre la materia, de manera que no era posible crear una cultura en relación a las denominaciones de origen. Además, las normas se circunscribían de manera prácticamente exclusiva a la actividad vitivinícola, descartando la aplicación de las denominaciones de origen a otras actividades ${ }^{58}$.

Si bien la normativa vigente debió resolver estas falencias, comprobaremos que ello no fue plenamente logrado.

\section{NORMATIVA VIGENTE}

La normativa vigente está compuesta por la Ley de alcoholes y los Decretos de Zonificación, además de los tratados comerciales que han reconocido denominaciones de origen. Debido a la modificación de la Ley de propiedad industrial del año 2005, se incorporó la protección de indicaciones geográficas y denominaciones de origen al régimen general de propiedad industrial en Chile, que considera la protección a través del sistema de registro.

Esta variedad normativa constituye un marco reglamentario que conforma un sistema ambiguo y descoordinado, donde queda al descubierto una tendencia a mantener vigentes diversas técnicas de protección que generan cierto grado de confusión normativa. Al cabo del análisis de la normativa vigente podremos considerar la conveniencia de establecer un sistema refundido de protección que evite la dispersión actual.

\section{a) Denominaciones de origen establecidas por ley: Pisco, Pajarete y Vino Asoleado}

En 1985 se promulga la Ley 18.455, actualmente vigente, la que protege las denominaciones de origen del Pisco, Pajarete y Vino Asoleado y faculta al Presidente de la República para establecer Zonas Vitícolas, y para autorizar el uso de denominaciones de origen $^{59}$.

La Ley de Alcoholes establece las condiciones para usar las denominaciones de origen Pisco, Pajarete y Vino Asoleado, y encarga la dictación de un reglamento específico para determinar las condiciones, características y modalidades que deberán cumplir las zonas vitícolas y las denominaciones de origen de vinos y destilados. Para usar la denominación de origen Pisco, queda establecido el tipo de alcohol, las variedades de uva y el lugar geográfico donde se deben plantar las vides (artículo 56).

58 JAQUIER y AREYUNA (2004) pp. 113 ss.

59 Las Zonas Vitícolas han sido establecidas por el D.S. Agricultura N 464 de 1995, sobre zonificación vitícola. 
La denominación Pisco queda reservada para el aguardiente producido y envasado en las regiones III y IV, en unidades de consumo. Para llevar el nombre de Pisco, esta bebida alcohólica debe ser elaborada por destilación de vino genuino potable, proveniente de las variedades de vides que determine el reglamento (artículo 28).

El Reglamento de la denominación de origen Pisco se publicó el 27 de mayo del año 2000, y está contenido en el Decreto de Agricultura $N^{\circ}$ 521. Este es el primer y único caso de denominación de origen con reglamento dictado, por lo que servirá de modelo de futuros casos de denominaciones de origen legales, y al mismo tiempo puede servir de pauta para reglamentos de denominaciones de origen registrales.

La Ley de Alcoholes establece los productos que serán considerados falsificados, exigiendo que la bebida alcohólica con denominación de origen sea producida, elaborada o envasada en las regiones y áreas establecidas por la ley o que se establezcan por Decreto Supremo (artículo 57). Igualmente, en su proceso de producción o elaboración no puede haber intervención alguna de materias primas procedentes de regiones o áreas distintas a las establecidas en la ley o por Decreto Supremo, ni con variedades de uvas distintas a las señaladas en la ley (artículo 57).

El reglamento de la Ley 18.455 fija normas sobre producción, elaboración y comercialización de alcoholes etílicos, bebidas alcohólicas y vinagres, definiendo qué bebidas pueden recibir el nombre de Clery, Cognac, Armagnac, Brandy, Gin, Vodka y Whisky. Estas no son consideradas en calidad de denominaciones de origen, sino simplemente en cuanto a tipos de bebidas alcohólicas, de manera que de acuerdo a la ley, podemos considerarlas como nombres genéricos para designar alcoholes con sus características respectivas.

El título V del Reglamento trata sobre la denominación de origen. Señala que otro reglamento específico determinará las condiciones, características y modalidades que deberán cumplir las zonas vitícolas y las denominaciones de origen de vinos y destilados (artículo 55). Esta norma sería el Decreto $N^{\circ} 464$ de zonificación vitícola de 1995.

Adicionalmente, el Reglamento define lo que se considera vino adulterado y vino falsificado. Un vino se considera adulterado o falsificado cuando contiene ingredientes prohibidos o en cantidades superiores a las prohibidas.

Se consideran falsificadas las bebidas alcohólicas con denominación de origen que hayan sido producidas, elaboradas o envasadas fuera de las regiones y áreas establecidas por la ley o que se establezcan por Decreto Supremo; las con denominación de origen en cuyo proceso de producción o elaboración hayan intervenido total o parcialmente materias primas procedentes de regiones o áreas distintas a las establecidas en la ley o que se establezcan por Decreto Supremo; y los piscos elaborados con variedades de uvas distintas a las señaladas en el artículo $5^{\circ}$ del Decreto $N^{\circ} 521$ del Ministerio de Agricultura (artículo 57 Decreto $N^{\circ} 78$ ).

Se reglamenta el uso del nombre "Pisco Sour", expresión propia de un cóctel producido y envasado en las Regiones III y IV, preparado con pisco, zumo de limón o saborizante natural del mismo. El detalle de esta particular denominación de origen indica la graduación alcohólica, y declara que se acepta que esta bebida se prepare con 
zumo de otras frutas cítricas o saborizantes naturales de las mismas, en cuyo caso al producto deberá nominarse "Pisco Sour" seguido del nombre de la fruta que corresponda (artículo 57 Decreto $N^{\circ} 78$ ).

Estos detalles van más allá de resguardar al consumidor de la posibilidad de engaño para imponer exigencias que son de tipo comercial, lo que hace cuestionar la necesidad de que el legislador se avoque a materias fácilmente resueltas por normas generales de etiquetado.

\section{b) Indicaciones geográficas y denominaciones de origen sujetas a registro}

A partir de diciembre del año 2005 comenzó a regir una reforma a la Ley 19.039. Se incorporaron, dentro de las nuevas categorías de derechos de propiedad industrial, las indicaciones geográficas y las denominaciones de origen. Se introdujo en nuestra legislación interna el concepto de indicación geográfica y se otorgó una definición legal al de denominación de origen.

El objetivo general de esta reforma fue ajustar nuestra ley a las normativas internacionales establecidas en acuerdos de comercio suscritos por Chile $\mathrm{y}$, específicamente, con aquellas regulaciones y directrices emanadas de la $\mathrm{OMC}^{60}$.

Posteriormente, se vio la necesidad de introducir nuevas modificaciones a la ley por medio de la reforma del año 2007, la que vino a precisar las causales de irregistrabilidad de indicaciones geográficas y denominaciones de origen, además de precisar aspectos de la regulación jurídica que podían producir dificultad interpretativa en consideración a las indicaciones geográficas o denominaciones de origen reconocidas por tratados internacionales ratificados por Chile.

Las indicaciones geográficas y denominaciones de origen quedan reguladas por las normas de la Ley 19.039 y por los reglamentos específicos de uso que se aprueben. No obstante, no se derogó la anterior normativa vigente en materia de regulación de denominaciones de origen. La ley mantiene la vigencia de las disposiciones que regulan las denominaciones de origen del Pisco, Pajarete y Vino Asoleado, y las que se refieren a la zonificación vitícola, prevaleciendo respecto de ellas las normas específicas contenidas en la Ley de Alcoholes 18.455 (artículo 93, inciso $1^{\circ}$ ).

La Ley de Propiedad Industrial define indicaciones geográficas y denominaciones de origen en concordancia con los acuerdos internacionales suscritos por Chile ${ }^{61}$. En ambos casos queda establecida la vinculación del origen de un producto con un lugar geográfico específico. En el caso de la indicación geográfica, este solo elemento es suficiente, mientras que en el caso de la denominación de origen, se requieren mayores distintivos: factores naturales y humanos, que tengan consecuencias sobre las cualidades del producto.

Antes de la reforma de la Ley 19.039, nuestra legislación solo protegía como denominación de origen a las bebidas alcohólicas y espirituosas, no existiendo casos de denominación de origen registrada para productos agrícolas o artesanales ajenos a este

${ }^{60}$ JAQUIER y AREYUNA (2004) pp. 113 ss.

${ }^{61}$ Ver artículo 92 letras a y b de la Ley 19.039. 
ámbito. La definición actual que proporciona la ley permite incluir dentro de este concepto a otros productos ${ }^{62}$.

La función de mantener y custodiar los registros de indicaciones geográficas y denominaciones de origen corresponde al Instituto Nacional de la Propiedad Industrial $^{63}$, al igual que lo hace con los registros de marcas y patentes.

La ley busca resguardar el uso y control de la indicación o denominación solicitada, exigiendo que junto a la solicitud se acompañe un proyecto de reglamento específico de la indicación o denominación solicitada (artículo 97 f). Además, se exige informe favorable del Ministerio de Agricultura, en las solicitudes de indicaciones geográficas o denominaciones de origen de productos silvoagropecuarios o agroindustriales (artículo 98).

Una vez concedido, el registro de una indicación geográfica o denominación de origen tendrá duración indefinida, pero podrá ser modificado en cualquier tiempo cuando cambie alguna de las circunstancias fundamentales. La modificación deberá sujetarse al procedimiento de registro, en cuanto corresponda (artículo 100).

El titular del registro de indicación geográfica o denominación de origen deberá representar a un grupo significativo de productores, fabricantes o artesanos, cualquiera sea su forma jurídica, cuyos predios o establecimientos de extracción, producción, transformación o elaboración se encuentren dentro de la zona de delimitación establecida por la indicación geográfica o denominación de origen solicitada y cumplan con los demás requisitos señalados por la ley ${ }^{64}$. Este carácter colectivo, no excluyente de las indicaciones geográficas y denominaciones de origen permite que todos los productores, fabricantes o artesanos que desempeñan su actividad dentro de la zona geográfica delimitada, inclusive aquellos que no estuvieran entre los que solicitaron el reconocimiento inicialmente, tengan derecho a usar la indicación geográfica o denominación de origen en relación con los productos señalados en el Registro, siempre que cumplan con las disposiciones que regulan el uso de las mismas.

\section{c) Indicaciones geográficas y denominaciones de origen protegidas por tratados} bilaterales suscritos por Chile

Los regímenes descritos anteriormente deben complementarse con los tratados internacionales suscritos por Chile, en particular con los acuerdos comerciales generales y los tratados de libre comercio.

${ }^{62} \mathrm{Al}$ momento de escribir este artículo, están en trámite de registro las denominaciones de origen Maiz Blanco Gigante Cuzco (solicitud No 801.166) para maíz, Chulucanas (solicitud N 801.167) para cerámica, Monoi de Tahiti (solicitud $\mathrm{N}^{\circ}$ 839.865) para distinguir productos cosméticos, y Parmigiano Reggiano (solicitud $\mathrm{N}^{\circ} 840,112$ ) para distinguir queso, además de Montefalco Sagrantino (solicitud $\mathrm{N}^{\circ} 725.624$ ) que distingue un vino tinto producido en la región italiana de Montefalco y que se encuentra protegida por el Acuerdo de Asociación con la Unión Europea.

${ }^{63}$ Ley 20.254 que crea el Instituto Nacional de la Propiedad Industrial, publicada en el Diario Oficial el 14 de abril, 2008.

${ }^{64}$ También podrán solicitar el reconocimiento de una indicación geográfica o denominación de origen las autoridades nacionales, regionales, provinciales o comunales, cuando se trate de indicaciones geográficas o denominaciones de origen ubicadas dentro de los territorios de sus respectivas competencias (artículo 94). 
(i) Acuerdo de Asociación entre la Comunidad Europea y sus Estados miembros, y la República de Chile ${ }^{65}$.

El Acuerdo de Asociación entre Chile y la Comunidad Europea trae consigo importantes beneficios para los distintos sectores productivos de nuestro país. En lo que respecta a la materia que nos ocupa, se efectúa un reconocimiento y protección recíproca de indicaciones geográficas de denominaciones del vino (Anexo V) y de bebidas espirituosas y aromatizadas (Anexo VI). Usa el término indicaciones geográficas en el sentido que lo define ADPIC. No se define el término denominación de origen, el que se usa como mención de calidad, al igual que "reserva", "superior" y "clásico" (Apéndice IV, Anexo V, Lista A).

En lo que se refiere a las indicaciones geográficas de vinos, establece un largo listado de denominaciones pertenecientes a los distintos países de la Unión Europea, todos en relación a vinos, bebidas espirituosas y bebidas aromatizadas. En el caso de las indicaciones geográficas de vino chilenas, se trata de denominaciones reconocidas por nuestro ordenamiento jurídico por el decreto de zonificación vitícola. Pero la lista de denominaciones de bebidas espirituosas chilenas contempla denominaciones que no estaban formalmente protegidas en nuestro ordenamiento interno. Descontando el caso del Pisco, se protegen nuevas denominaciones: Aguardiente chileno, Brandy chileno, Whiskey chileno, Gin chileno, Vodka chileno, Ron chileno, Guindado chileno, Anís chileno y Vermouth chileno (protegida en cuanto bebida aromatizada).

Producto del Acuerdo de Asociación, Chile debió renunciar al uso de algunas denominaciones y cancelar marcas para el uso exclusivo de los países de la Unión Europea, como por ejemplo Champagne, cuyo uso en cuanto indicación geográfica debió suspenderse al momento de entrar en vigor el Acuerdo, y por otra parte, las marcas que contenían el término debieron y deberán cancelarse en el plazo de 5 años para las exportaciones (2008) y 12 años en nuestro mercado interno (2015) (artículo $7 \mathrm{n}^{\circ} 2$ Anexo V).

Las cancelaciones de marcas a que dé origen el Acuerdo constituyen una expropiación por lo que debe procederse al cálculo y pago de las respectivas indemnizaciones a sus titulares, en los plazos correspondientes.

El Acuerdo de Asociación considera que las indicaciones geográficas constituyen derechos de propiedad intelectual. Pero solo se refiere a indicaciones relacionadas a licores y al vino, de manera que no extiende la protección a productos alimenticios o de fabricación artesanal.

(ii) Tratado de Libre Comercio entre Estados Unidos de América y Chile ${ }^{66}$. El capítulo diecisiete del TLC entre Chile y Estados Unidos se refiere a la Propiedad Intelectual, señalando expresamente que se construye sobre la base de los tratados

${ }^{65}$ En vigor desde el 3 de febrero del año 2003, mediante el Decreto Supremo $\mathrm{N}^{\circ} 28$ de Relaciones Exteriores.

${ }^{66}$ En vigor desde el 31 de diciembre del año 2003, mediante Decreto Supremo No 312 de Relaciones Exteriores. 
internacionales existentes en ese campo, indicando en forma particular el Acuerdo sobre los Aspectos de la Propiedad Intelectual relacionadas con el Comercio de la OMC, reafirmando los derechos y obligaciones establecidos por este cuerpo normativo.

El TLC entre Chile y EE.UU. define indicaciones geográficas señalando que son las que identifica un producto como originario del territorio de una Parte, o de una región o localidad de ese territorio, cuando determinada calidad, reputación u otra característica del producto sea imputable fundamentalmente a su origen geográfico (artículo 17.4). En el artículo referente a las marcas comerciales incluye la posibilidad de proteger las indicaciones geográficas, junto con las marcas colectivas y de certificación, señalando expresamente, que las indicaciones geográficas pueden constituir una marca de fábrica o de comercio (artículo 17.2, $\mathrm{n}^{\circ} 1$, pie de página 3).

Cualquier signo o combinación de signos, tales como palabras (incluidos los nombres geográficos y de personas, letras, números, elementos figurativos y colores) de cualquier forma que sea, podrán optar a la protección o reconocimiento como una indicación geográfica. No se define denominación de origen.

El Tratado busca simplificar y transparentar los procesos para obtener la protección de las indicaciones geográficas y reconoce el principio de exclusividad incorporado en el Convenio de París y en el Acuerdo sobre los ADPIC, con respecto a los derechos sobre marcas de fábrica y de comercio.

El aparente menor grado de protección de las indicaciones geográficas en el TLC con Estados Unidos en comparación con el Acuerdo con la Unión Europea, se debe a que entre ambas jurisdicciones existen importantes diferencias a la hora de enfrentar la problemática de protección de esta forma de propiedad intelectual.

En el caso de la Unión Europea se privilegia un sistema omnicomprensivo que otorgue la mayor protección a las indicaciones geográficas, según estas se encuentren reconocidas por los Estados. Las indicaciones geográficas y denominaciones de origen se registran como tales, y son protegidas por normas de rango legal, e incluidas en largos listados. Por el contrario, en Estados Unidos, se prefiere un sistema que privilegia el concepto de derecho privado de la indicación geográfica, asimilándola a la protección marcaria, protegiendo las indicaciones geográficas como marcas colectivas o de certificación.

El TLC con Estados Unidos protege cinco denominaciones de origen particulares, pero contrario a lo que podría esperarse, no están en el capítulo diecisiete, sino en el capítulo tres, sobre Trato nacional y acceso de mercancías al mercado. En este capítulo no se las designa con el nombre de indicaciones geográficas ni denominaciones de origen, sino que como productos distintivos. Quedan así protegidas las indicaciones geográficas Bourbon Whiskey y Tennesee Whiskey para productos elaborados en Estados Unidos de conformidad con sus leyes y regulaciones; y Pisco, Pajarete y Vino Asoleado para productos elaborados en Chile de conformidad con sus leyes y regulaciones (Capítulo Tres, Sección E, artículo 3.15).

\section{(iii) Otros TLC}

Chile ha firmado tratados de libre comercio con Canadá, República de Corea, Asociación de Libre Comercio Europea (EFTA), México, Centro América y China. Los 
acuerdos con Canadá, República de Corea y México establecen protección para las denominaciones de origen respectivas para el vino y el licor. No así para otros productos. El acuerdo con China limita la lista de indicaciones geográficas chilenas al Pisco Chileno. El resto de los acuerdos no establecen normas relativas a las indicaciones geográficas ni denominaciones de origen.

Resulta interesante comprobar cómo la tendencia de liberalizar los mercados ha ido adquiriendo cada vez mayor fuerza a través de múltiples tratados y acuerdos comerciales, y, sin embargo, estos mismos tratados han tendido a incluir la noción de protección de las indicaciones geográficas. Esta inclusión podría considerarse un contrasentido, en cuanto constituye una forma de proteccionismo. No obstante, resulta evidente que aún en un mundo globalizado, donde la libertad de movimiento de bienes y personas es cada vez mayor, subsiste un vivo interés por proteger estos derechos de carácter eminentemente local.

\section{SOluCión de CONFlictos POR indicACiONES GEOGRÁficAs Y DENOMINACIONES DE ORIGEN}

Frente a esta multiplicidad de normas y sistemas paralelos para establecer indicaciones geográficas y denominaciones de origen, resulta inevitable cierto grado de confusión en cuanto a la mejor manera de proteger una indicación geográfica o denominación de origen en particular. El asunto se torna aún más complejo cuando se quiere definir la manera de resolver controversias que pudieran surgir en torno a la legítima titularidad o derecho de uso de una indicación geográfica o denominación de origen en particular.

a) Situación de indicaciones geográficas y denominaciones de origen protegidas por ley, decreto supremo o tratado internacional

En el caso de las indicaciones geográficas y denominaciones de origen establecidas por ley, decreto supremo o tratado internacional no corresponde hablar de titularidad, ya que se trata de denominaciones de origen reconocidas, que tienen la característica de ser susceptibles de ser utilizadas por cualquiera que se asiente en el territorio específico y produzca los bienes determinados, de acuerdo a los procedimientos requeridos. En estos casos, se pueden producir problemas respecto al uso legítimo que en definitiva la autoridad estará llamada a resolver por medio de controles que aseguren que los productores están cumpliendo con los requisitos para poder utilizar la denominación. Organismos como el SAG tendrán esta obligación y facultades para impedir que se comercialicen productos equivocados con denominación de origen.

Terceros que quieran resguardar el correcto uso de la indicación geográfica o denominación de origen particular, deberán accionar frente a la autoridad administrativa para efectos de que ejerza el control que le corresponda y sancione a la entidad que incumple con la normativa.

Por su parte, un extranjero titular de una indicación geográfica o denominación de origen reconocida por tratado deberá estarse a lo señalado en el tratado correspondiente, lo que normalmente significará solicitar a su gobierno intervenir a su favor ante las autoridades del país. Esto exigirá al Estado decidir si amerita someter la situación al 
sistema de solución de conflictos que el propio tratado pueda establecer, o bien buscar los mecanismos de solución de controversias internacionales, partiendo normalmente por las negociaciones diplomáticas.

\section{b) Situación de indicaciones geográficas y denominaciones de origen protegidas por registro.}

Tratándose de un registro de denominación de origen obtenido en conformidad a la Ley 19.039, las opciones para resolver conflictos son mucho más claras. Los tribunales ordinarios de justicia son competentes para ver las acciones civiles relativas al derecho de usar una indicación geográfica o denominación de origen registrada, y las destinadas a impedir el uso ilegal de las mismas (artículo 104).

En el caso de indicaciones geográficas o denominaciones de origen registradas que identifiquen vinos y bebidas espirituosas, procederán acciones civiles cuando se emplee una indicación geográfica o denominación de origen sin tener derecho a usarla, o traducida, o cuando se acompañe de términos como "clase", "tipo", "estilo", “imitación”, u otras análogas, e incluso cuando se indique el verdadero origen del producto (artículo 104).

La ley sanciona con multa a beneficio fiscal el uso malicioso e ilegítimo de una indicación geográfica o denominación de origen registrada, el uso comercial de una indicación geográfica o denominación de origen no inscrita, caducada o anulada, el uso comercial de una denominación de origen simulada, o el uso de envases o embalajes que lleven una indicación geográfica o denominación de origen registrada, sin tener derecho a usarla (artículo 105). Los condenados serán obligados al pago de las costas, daños y perjuicios causados a los legítimos usuarios de la indicación geográfica o denominación de origen.

Los utensilios y los elementos directamente empleados para la comisión de cualquiera de los delitos mencionados en este artículo y los objetos con indicaciones geográficas o denominaciones de origen falsificadas caerán en comiso. Tratándose de los objetos con indicación geográfica o denominación de origen falsificada se procederá a su destrucción. En el caso de los utensilios o elementos utilizados, será facultad del juez competente decidir sobre su destino, pudiendo ordenar su destrucción o su distribución benéfica.

Las acciones civiles antes señaladas no excluyen el ejercicio de las acciones penales que pudieran corresponder, además de las acciones por competencia desleal que podrían también ejercerse de acuerdo a la Ley 20.169, de 2007, sobre competencia desleal.

\section{c) Procedencia de las acciones establecidas en la Ley sobre Competencia Desleal}

La ley que regula la competencia desleal permite calificar una conducta como un acto de competencia desleal aun cuando sean procedentes respecto de esa misma conducta, y ante los tribunales competentes, una o más acciones reguladas por la Ley 19.039 sobre propiedad industrial (artículo 2 Ley 20.169). No hay tal norma referida a la Ley de alcoholes, ni al Decreto Supremo de zonificación vitícola, y tampoco a los tratados internacionales. Por lo que la situación de procedencia de una acción basada en esta ley es más segura tratándose de las denominaciones de origen registrales. 
Contra los actos de competencia desleal pueden ejercerse, conjunta o separadamente, la acción de cesación del acto o prohibición del mismo, acción declarativa de acto de competencia desleal, acción de remoción de los efectos producidos por el acto, y acción de indemnización de perjuicios ocasionados por el acto (artículo 5). Todas estas acciones serían por tanto procedentes para el resguardo de una indicación geográfica o denominación de origen registrada en conformidad a la Ley 19.039. Queda la duda de su procedencia respecto de una indicación geográfica o denominación de origen de tipo legal, reglamentaria o por tratado internacional.

Es competente para conocer de las causas de esta ley el juzgado de letras en lo civil del domicilio del demandado o del actor, a elección de este último (artículo 8). Se trata de acciones que se tramitan de acuerdo con las normas del procedimiento sumario (artículo 9).

En el caso de sentencia firme que establezca que han existido uno o más actos de competencia desleal, el tribunal que la dictó deberá remitir todos los antecedentes del juicio al Fiscal Nacional Económico, quien tendrá la facultad de requerir al Tribunal de Defensa de la Libre Competencia, atendidas la gravedad de la infracción o la extensión del perjuicio provocado, la aplicación de la multa correspondiente (artículo 10).

4. EVALUACIÓN GENERAL: HACIA UN SISTEMA REGISTRAL INTEGRAL DE LAS DENOMINACIONES DE ORIGEN

Como hemos podido comprobar, coexisten en Chile tres sistemas para establecer denominaciones de origen: por Ley (Ley de alcoholes) y Decreto Supremo (zonificación vitícola), por tratados internacionales y por registro (Ley 19.039). La justificación tras la coexistencia de estos tres sistemas es de índole histórica, por cuanto se fueron sucediendo las normas y los tratados en el tiempo, pero no justifica que el legislador no haya previsto una mejor solución que permita refundir la normativa de protección de las denominaciones de origen en un sistema único o al menos dual que permita una mayor certeza jurídica para los titulares de estos derechos.

El sistema legal es rígido en cuanto establece tres denominaciones de origen: Pisco, Pajarete y Vino Asoleado. Cualquier interés por introducir cambios en la ley, requiere poner en marcha el aparato legislativo con todas las dificultades que ello conlleva. A su vez la protección por Decreto Supremo, por el cual se fija la zonificación vitícola, es igualmente rígido al requerir que la autoridad cambie la zonificación. La situación de rigidez de los tratados internacionales es probablemente la más compleja de todas ya que cualquier modificación requiere no solo la voluntad de uno, sino que de dos o más Estados.

Los casos anteriores limitan las indicaciones geográficas y denominaciones de origen a productos muy específicos según la ley y a productos vitivinícolas en el caso de la potestad reglamentaria. Por el contrario, el sistema registral ofrece toda la flexibilidad propia del sistema marcario, el que ha resultado adecuado para proteger los intereses de quienes se dedican a la actividad comercial que es esencialmente dinámica y ágil.

Por lo demás el sistema registral resulta más transparente en su manera de abordar el establecimiento de nuevas indicaciones geográficas y denominaciones de origen, otor- 
ga la flexibilidad necesaria para establecer nuevas denominaciones más allá del ámbito del vino y de las bebidas espirituosas, permite que terceros puedan conocer de los procesos de registro y eventualmente oponerse a ellos.

Considerando que es la misma autoridad la que se encarga del registro de marcas y del registro de denominaciones de origen e indicaciones geográficas, tiene la ventaja adicional que permite que esta autoridad esté más sensibilizada a que potenciales conflictos entre unas y otras se resuelvan de diversas maneras, ya que puede haber casos en que deba primar una sobre otra, o bien en que deban coexistir ${ }^{67}$.

Siguiendo en la línea de la solución de conflictos, el establecimiento de indicaciones geográficas y denominaciones de origen por registro tiene ventajas en lo que se refiere a conflictos, tanto en el proceso del establecimiento de nuevas indicaciones geográficas y denominaciones de origen, como en el caso de infracción, permitiendo contar con los tipos penales y de competencia desleal que permitirían accionar contra quienes hicieran un uso indebido de una indicación geográfica o denominación de origen ajena.

Para efectos de lograr un sistema único, habría que dictar una norma legal que exija al Departamento de Propiedad Industrial incluir en el registro de indicaciones geográficas y denominaciones de origen, las ya establecidas por ley, decreto supremo y acuerdos internacionales.

De esta manera una mayor flexibilidad del sistema redunda en su beneficio en cuanto permite reaccionar con mayor rapidez ante los cambios que se pueden generar en las indicaciones geográficas y denominaciones de origen ya establecidas, en cuanto estas pueden caer en desuso o modificar su ámbito de acción.

\section{CONCLUSIONES}

Una de las mayores dificultades con las que se ha topado la protección internacional de las indicaciones geográficas ha sido la diversidad de conceptos nacionales para este término. No obstante, el fundamento siempre es el mismo: el interés por dar protección a los nombres de productos locales que contribuyen a la formación de la identidad cultural de una nación o localidad.

Las indicaciones geográficas son denominaciones que identifican un producto como originario de un país, región o localidad, cuando la calidad, reputación u otra característica fundamental del mismo sea imputable fundamentalmente a su origen geográfico. Entre las indicaciones geográficas se distinguen las denominaciones de origen que constituyen una especie de indicación geográfica de mayor exigencia, en cuanto requiere que además de la vinculación geográfica, se compruebe que se ha cumplido con procedimientos naturales y humanos adicionales que inciden en la calidad del producto. Tanto denominaciones de origen como indicaciones geográficas simples deben tener

\footnotetext{
${ }^{67}$ Puede darse el caso en que el Instituto Nacional de Propiedad Industrial llegue a la convicción que es posible la coexistencia entre marcas e indicaciones geográficas o denominaciones de origen, o de estas últimas entre sí, en resolución definitiva determinará las condiciones en las cuales deben ser usadas para evitar la inducción a error o confusión al público consumidor (artículo 96 bis A, Ley 19.039).
} 
reglamentos específicos que definan el ámbito de las normas aplicables a cada uno de estos conceptos, constituyendo estos reglamentos la norma institucional fundamental de la denominación, ya que en ella se regulan aspectos organizativos, jurídicos y técnicos.

Sin perjuicio de que las denominaciones de origen son una especie de indicación geográfica, comprobamos que estas reciben una mayor atención en el siglo XIX gracias al desarrollo de la industria del vino. Francia es pionera en la protección de las denominaciones de origen, la que luego se internacionaliza con los primeros tratados de propiedad intelectual, donde el concepto rara vez se define, pero sí se incluye para efectos de asegurar su protección.

El paso del tiempo ha ido definiendo y perfilando la naturaleza jurídica de la protección de las indicaciones geográficas y denominaciones de origen. Durante gran parte del siglo XX su protección se consideraba exclusivamente dentro del régimen de protección de los derechos del consumidor y de las normas contra la competencia desleal. Evoluciona esta protección para reconocer su calidad de derechos de propiedad intelectual. Esta evolución se comprueba tanto a nivel internacional como en el caso de Chile, donde la última reforma los ha incluido como derechos en la ley de propiedad industrial.

Se distinguen dos sistemas de protección. Europa lidera la tendencia a que las indicaciones geográficas y denominaciones de origen se establezcan por sistemas reglamentarios muy controlados. Estados Unidos ha procedido de manera diferente. Se ha tratado el tema de las indicaciones geográficas como una materia más próxima a las marcas comerciales, lo que privilegia el interés actual en el uso comercial de los términos, más que en el proteccionismo abstracto. De hecho, se usa el registro de las marcas colectivas o de certificación como mecanismo para proteger las indicaciones geográficas.

La búsqueda de acuerdos internacionales en esta materia ha debido sortear estas distintas posiciones, logrando acuerdos de compromiso en base a establecer un mínimo territorio común. Este territorio común se ha logrado con el concepto de protección de las indicaciones geográficas, evitando el de denominación de origen, que es más debatido por otorgar mayor protección. Así se procedió en el Acuerdo sobre Aspectos de Propiedad Intelectual relativo al Comercio (ADPIC).

En Chile, al igual que en Francia, el desarrollo normativo comienza con la regulación de las denominaciones de origen en el ámbito de la industria del vino. La regulación es legal y por decreto. Con la firma de ADPIC, Chile incorpora la protección de indicaciones geográficas y define denominaciones de origen e indicaciones geográficas de manera más general en cuanto derecho de propiedad intelectual.

La ley de propiedad industrial ha creado el registro de indicaciones geográficas y denominaciones de origen sin derogar las normas que establecían otras denominaciones de origen. Es así como hoy conviven tres sistemas: por ley, por tratados internacionales y por registro.

El registro es el sistema más dinámico ya que permite que cualquiera solicite la indicación geográfica o denominación de origen requerida, sin necesidad de hacer lobby para cambiar una ley o para modificar un tratado. Al mismo tiempo, da seguridad ya que son registros indefinidos. 
Las ventajas del sistema registral son muchas: el registro único permitiría mayor flexibilidad y dinamismo en el sistema, logrando que se registren solo aquellas denominaciones que realmente sean de interés de proteger en Chile, evitando trabar el sistema con una infinita multitud de denominaciones de origen respecto de las cuales no existe interés de ser usadas en nuestro mercado.

El sistema registral es más transparente ya que sus requisitos de obtención y mantención están claramente establecidos, con sistemas de publicidad previos al registro que permiten que terceros que pudieran tener objeciones a los registros puedan hacer valer sus reclamos antes de que se constituyan derechos sobre los términos. De esta manera se asegura una mejor coexistencia entre indicaciones geográficas y marcas comerciales, ya que por ley y por tratado es menor la posibilidad de que terceros se enteren antes de que sea demasiado tarde.

El sistema registral ofrece mayor seguridad jurídica para los titulares de registros al contemplar recursos legales, y ofrecer un sistema claro y expedito de resolución de conflictos, que incluye recursos ante tribunales especializados: el Instituto Nacional de Propiedad Industrial, el Tribunal de la Propiedad Industrial y el Tribunal de la Libre Competencia. Los registros tienen duración indefinida pero permiten modificación si cambian las circunstancias, de manera que muestran ser más dinámicos.

La propuesta es que se establezca el ingreso obligatorio al registro de las indicaciones geográficas y denominaciones de origen establecidas por ley y por tratados, para integrar un sistema de protección único. Esta solución es plenamente aplicable para el caso de las indicaciones geográficas y denominaciones de origen reconocidas en los tratados internacionales, ya que comprobamos que junto con enunciar la protección que se debe dar a las indicaciones extranjeras resulta conveniente supeditar la protección local al interés real de los titulares por obtener el registro en el país, de manera de no limitar en exceso el comercio.

\section{BIBLIOGRAFÍA CITADA}

Álvarez Enríquez, Carmen Paz (1998): “Instituciones del Derecho del Vino. En Especial de las Denominaciones de Origen”, Rev. chil. derecho, vol. 25 No 4, pp. 757-792.

Álvarez Enríquez, Carmen Paz (2001): Derecho del Vino. Denominaciones de Origen (Santiago, Editorial Jurídica de Chile) 150 pp.

Calaguas, Mark J. (2006): "A Rosé by Any Other Name: Protecting Geographical Indications for Wines and Spirits in China", Loyola University Chicago International Law Review, vol. 3, issue 2, pp. 257-279.

Claro Solar, Luis (1930): Explicación de Derecho Civil Chileno y Comparado, tomo VI (Santiago, Cervantes) 675 pp.

CONRAD, Albrecht (1996): "The Protection of Geographical Indications in the Trips Agreement", Trademark Reporter, vol. 86, pp. 11-46.

FernándeZ-NovoA, Carlos (2004): Tratado sobre Derecho de Marcas (Madrid, Marcial Pons) 755 pp. 
GangJEE, Dev (2007): "Quibbling Siblings: Conflicts between Trademarks and Geographical Indications", Ken L. Rev., vol. 82: 3, pp. 1253-1293.

GÓmeZ Segade, José A. (2001): Tecnología y Derecho: estudios jurídicos del Prof. Dr. h. c. José Antonio Gómez Segade recopilados con ocasión de la conmemoración de los XXV años de cátedra (Madrid, Marcial Pons) 967 pp.

JAQUiER LeHUEDÉ, Eduardo y AREYUnA NAVARro, Rafael (2004): “Las Denominaciones de Origen en la Actual Legislación. Propuestas para su complemento y actualización”, Revista de Derecho, Universidad Católica del Norte - Sede Coquimbo, año 11 $\mathrm{N}^{\circ} 2$, pp. 113-123.

Larraguibel, Santiago (1995): Tratado sobre la Propiedad Industrial, tomo 2 (Santiago, Editorial Jurídica ConoSur) 330 pp.

LÓPEZ BeníteZ, Mariano (1996): Las denominaciones de origen (Barcelona, Cedecs) 201 pp.

Lorenzini BArríA, Jaime (2000): El Régimen de Propiedad Industrial en la O.M.C. (Santiago, Editorial Jurídica ConoSur) 306 pp.

O'Connor, Bernard (2004): "Sui Generis Protection of Geographical Indications", Drake Journal of Agricultural Law, vol. 9, pp. 359-388.

ORGANiZACIÓN DE LA ViÑA Y EL VINO: "OIV - Historia” [fecha de consulta 26 agosto 2009]. Disponible en <http://news.reseau-concept.net/pls/news/p_entree?i_sid=\&i_ type_edition_id=20772\&i_section_id=20792\&i_lang=33>

Orozco Argote, Iris del Rocío (2008): "Las denominaciones de origen en México", Actualidad Jurídica, No 17, pp. 385-402.

RISANG AYU, Miranda (2006): "How Does Australia Regulate the Use of Geographical Indication for Products Other than Wines and Spirits?", Macquarie Journal of Business Law, vol. 3, pp. 1-21.

Ruiz Tagle Vial, Pablo (2001): Propiedad Intelectual y Contratos (Santiago, Editorial Jurídica de Chile) $681 \mathrm{pp}$.

Schiavone, Elena (2003): "Indicaciones Geográficas", Derechos Intelectuales No 10, Editorial Astrea, Buenos Aires, pp. 13-38.

SCHMitz VACCARO, Christian (2005): Propiedad Intelectual a la Luz de los Tratados de Libre Comercio (Santiago, LexisNexis) 392 pp.

TORSEN, Molly (2005): "Apples and Oranges: French and American Models of Geographic Indications Policies Demonstrate an International Lack of Consensus", Trademark Reporter, vol. 95, pp. 1415-1445.

United States Patent and Trademark Office: "Geographical Indication Protection in the United States" [fecha de consulta 26 agosto 2009]. Disponible en <http:// www.uspto.gov/web/offices/dcom/olia/globalip/pdf/gi_system.pdf>

\section{NORMAS CITADAS}

Ley No 11.256, Fija el texto refundido de las disposiciones vigentes sobre la Ley de Alcoholes y Bebidas Alcohólicas, Diario Oficial, 16 julio de 1954.

Ley No 17.105, sobre Alcoholes, Bebidas Alcohólicas y Vinagres, Diario Oficial, 14 abril de 1969. 
Ley No 18.455, sobre producción, elaboración y comercialización de alcoholes etílicos, bebidas alcohólicas y vinagres, Diario Oficial, 11 noviembre de 1985.

Ley No 19.039, Ley de Propiedad Industrial, Diario Oficial, 25 enero de 1991.

Ley No 19.996, Modifica la Ley 19,039 sobre Propiedad Industrial, Diario Oficial, 11 marzo 2005.

Ley No 20.254, Crea el Instituto Nacional de la Propiedad Industrial, Diario Oficial, 14 abril 2008.

Decreto Supremo No 257 de Agricultura, Establece denominación de origen para los vinos de las regiones del país que indica, Diario Oficial, 20 octubre de 1979.

Decreto Supremo No 82 de Agricultura, Establece Subregiones Vitivinícolas, Diario Oficial, 14 abril de 1980 .

Decreto Superemo No 78 de Agricultura, Reglamenta la Ley No 18.455, Diario Oficial, 23 octubre de 1986.

Decreto Supremo No 464 de Agricultura, Establece Zonificación Vitícola y fija normas para su utilización, Diario Oficial, 26 mayo de 1995.

Decreto Supremo No 521 de Agricultura, Fija Reglamento de la Denominación de Origen Pisco, 27 mayo de 2000.

Decreto con Fuerza de Ley $\mathrm{N}^{\circ} 1$ de Agricultura, Señala normas sobre plantaciones, replantes y trasplantes de viñas viníferas y de uvas de mesa; modifica la ley 11.256, que fijó el texto refundido de las disposiciones vigentes sobre la Ley de Alcoholes y Bebidas Alcohólicas, Diario Oficial, 3 octubre de 1967.

Decreto Ley N 2.753 de Agricultura, Modifica la ley 17,105, sobre Alcoholes, Bebidas Alcohólicas y Vinagres, Diario Oficial, 28 junio de 1979.

Decreto Supremo No 28, de Relaciones Exteriores, Promulga el Acuerdo por el que se establece una asociación entre la Comunidad Europea y sus Estados miembros, por una parte, y la República de Chile, Diario Oficial, 3 febrero de 2003.

Decreto Supremo N¹6, de Relaciones Exteriores, Promulga el Acuerdo sobre Aspectos de Propiedad Intelectual relativos al Comercio, Acuerdo de Marrakech por el que se establece la Organización Mundial del Comercio y los Acuerdos Anexos que se indican, Diario Oficial, 17 mayo de 1995.

Decreto Supremo No 425, de Relaciones Exteriores, Promulga el Convenio de París para la protección de la propiedad industrial adoptado en París el 20 de marzo de 1883, Diario Oficial, 30 septiembre de 1991.

Decreto Supremo No 312, de Relaciones Exteriores, Promulga el Tratado de Libre Comercio entre Estados Unidos de América y Chile, Diario Oficial, 31 diciembre de 2003.

Decreto Supremo No 1.020, de Relaciones Exteriores, Promulga el Tratado de Libre Comercio entre Canadá y Chile, Diario Oficial, 5 julio de 1997.

Decreto Supremo No 143, de Relaciones Exteriores, Promulga el Acuerdo de Asociación Económica Estratégica con Japón, Diario Oficial, 3 septiembre de 2007.

Arreglo de Lisboa relativo a la Protección de las Denominaciones de Origen y su Registro Internacional de 1958, Tratados Internacionales en Materia de Propiedad Intelectual, ASIPI, 1995. 


\section{JURISPRUDENCIA CITADA}

Consorzio del Prosciutto di Parma v. Parma Sausage Products Inc., 23 U.S.P.Q.2d (BNA) 1894, 1992 WI. 2333379 (T.T.A.B. 1992)

Consorzio del Prosciutto di Parma v. Maple Leaf Meats Inc. [2001] F.C. 536 (Fed. Ct.) y [2002] Federal Court of Appeals 169. 
